\title{
Method selection for mercury removal from hard coal
}

\author{
Tadeusz Dziok ${ }^{1, *}$, Andrzej Strugała ${ }^{1}$ \\ ${ }^{1}$ AGH University of Science and Technology, Faculty of Energy and Fuels, Al. A. Mickiewicza 30, 30- \\ 059 Krakow, Poland
}

\begin{abstract}
Mercury is commonly found in coal and the coal utilization processes constitute one of the main sources of mercury emission to the environment. This issue is particularly important for Poland, because the Polish energy production sector is based on brown and hard coal. The forecasts show that this trend in energy production will continue in the coming years. At the time of the emission limits introduction, methods of reducing the mercury emission will have to be implemented in Poland. Mercury emission can be reduced as a result of using coal with a relatively low mercury content. In the case of the absence of such coals, the methods of mercury removal from coal can be implemented. The currently used and developing methods include the coal cleaning process (both the coal washing and the dry deshaling) as well as the thermal pretreatment of coal (mild pyrolysis). The effectiveness of these methods various for different coals, which is caused by the diversity of coal origin, various characteristics of coal and, especially, by the various modes of mercury occurrence in coal. It should be mentioned that the coal cleaning process allows for the removal of mercury occurring in mineral matter, mainly in pyrite. The thermal pretreatment of coal allows for the removal of mercury occurring in organic matter as well as in the inorganic constituents characterized by a low temperature of mercury release. In this paper, the guidelines for the selection of mercury removal method from hard coal were presented. The guidelines were developed taking into consideration: the effectiveness of mercury removal from coal in the process of coal cleaning and thermal pretreatment, the synergy effect resulting from the combination of these processes, the direction of coal utilization as well as the influence of these processes on coal properties.
\end{abstract}

\section{Introduction}

Mercury and its compounds are characterized by highly toxic properties and negatively affect the functioning of the human organisms [1]. It should be emphasized, that any amount of mercury emitted to the environment is a potential threat to life and health, which is caused by the natural biogeochemical cycle of mercury [2]. One of the main sources of mercury emission to the environment is that constituted by the coal utilization processes, in which mercury is commonly found [3-5]. This issue is particularly important for Poland, because the Polish energy production sector is based on brown and hard coal [6] and the forecasts show that this trend in energy production will continue in the coming years [7]. Moreover, it

\footnotetext{
* Corresponding author: tadeusz.dziok@agh.edu.pl
} 
should be pointed out, that Poland is a major producer of coke in the EU [8]. At the moment of the emission limits introduction, methods of reducing mercury emission will have to be implemented in Poland.

The amount of mercury emitted in the coal utilization processes may be reduced using a number of methods. One of these methods involves using coal with a relatively low mercury content. Obviously, the availability of such coals is limited. However, in the case of their absence, methods of mercury removal from coal can be applied. The currently used and developing methods include the coal cleaning process $[9,10]$ as well as the thermal pretreatment of coal (mild pyrolysis) [11-13]. It should be mentioned that the effectiveness of these methods varies for different coals. This is caused by the diversity in coal origin, various characteristics of coal, and especially by the various modes of mercury occurrence in coal $[9,14-16]$. The coal cleaning process allows for the removal of mercury occurring in mineral matter, mainly in pyrite. The thermal pretreatment of coal allows for the removal of mercury occurring in organic matter as well as in the inorganic constituents characterized by a low temperature of mercury release.

In this paper, guidelines for the selection of a method for mercury removal from hard coal were presented. The guidelines were developed considering the effectiveness of mercury removal from coal in the processes of coal cleaning and thermal pretreatment, the synergy effect resulting from the combination of these processes, the direction of coal utilization as well as the influence of these processes on coal properties.

\section{Aim of study}

The main aim of the study was to develop guidelines for the selection of a method for mercury removal from hard coal. To achieve that goal, the effectiveness of mercury removal from coal in the processes of coal cleaning and thermal pretreatment was determined. While developing the guidelines the direction of coal utilization as well as the influence of the analyzed processes on coal properties were taken into consideration.

\section{Experimental}

\subsection{Examination of the coal cleaning process}

Within the framework of the coal cleaning process investigations, the samples derived from domestic industrial plants (coal washing) as well as from demo plants (dry deshaling) were examined. Six washing plants of coking coals and two dry separators of steam coal: the air concentrating table (DD1-DD6 cases) and the X-ray optical separator (DD7 case) were analyzed. The content of mercury in raw coals and rejects derived from the coal cleaning process are given in Table 1 . The method of mercury content determination was previously presented in work [10].

The effectiveness of mercury removal from coal in the process of coal cleaning was determined using the Eq. (1).

$$
\eta_{c c}=\frac{H g_{\text {rejects' }} \cdot \gamma_{\text {rejects }}}{H g_{\text {raw }}}
$$

$\eta_{c c}$ - effectiveness of mercury removal from coal in the process of coal cleaning [\%],

$\mathrm{Hg}_{\text {raw }}$ - mercury content in raw coal $[\mu \mathrm{g} / \mathrm{kg}]$,

$H g_{\text {rejests }}$ - mercury content in rejects $[\mu \mathrm{g} / \mathrm{kg}]$,

$\gamma_{\text {rejects }}$ - yield of rejects [\%]. 
Table 1. Mercury content in raw coals and rejects derived from coal cleaning process.

\begin{tabular}{|c|c|c|c|}
\hline \multirow{2}{*}{\multicolumn{2}{|c|}{ Analyzed cases }} & \multicolumn{2}{|c|}{$\begin{array}{c}\mathrm{Hg}_{\mathrm{t}}{ }^{\mathrm{d}} \\
{[\mu \mathrm{g} / \mathrm{kg}]}\end{array}$} \\
\hline & & Raw coal & Rejects \\
\hline \multirow{6}{*}{$\begin{array}{l}\text { Coal } \\
\text { washing }\end{array}$} & CW1 & 65 & 49 \\
\hline & CW2 & 170 & 36 \\
\hline & CW3 & 60 & 17 \\
\hline & CW4 & 83 & 47 \\
\hline & CW5 & 117 & 98 \\
\hline & CW6 & 98 & 50 \\
\hline \multirow{7}{*}{$\begin{array}{l}\text { Dry } \\
\text { deshaling }\end{array}$} & DD1 & 113 & 319 \\
\hline & DD2 & 146 & 121 \\
\hline & DD3 & 88 & 162 \\
\hline & DD4 & 137 & 93 \\
\hline & DD5 & 95 & 78 \\
\hline & DD6 & 124 & 160 \\
\hline & DD7 & 86 & 157 \\
\hline
\end{tabular}

\subsection{Examination of the coal thermal pretreatment process (mild pyrolysis)}

For the purposes of examining the coal thermal pretreatment process, due to the lack of appropriate industrial and pilot plants in Poland, the studies were conducted on bench scale. The investigations were carried out using the laboratory equipment for coal thermal pretreatment in fixed bed - Fig.1. The thermal pretreatment of coal was performed for the following process parameters:

- final temperature: $300^{\circ} \mathrm{C}$,

- heating rate: $5^{\circ} \mathrm{C} / \mathrm{min}$,

- residence time at the final temperature: $30 \mathrm{~min}$,

- purge gas: nitrogen,

- purge gas flow: $5 \mathrm{dm}^{3} / \mathrm{min}$,

- sample weight: $500 \mathrm{~g}$,

- coal particle size: below $10 \mathrm{~mm}$.

Five hard coals were examined: two raw coking coals (CW3 and CW5) and three steam coals (SC1, SC2 and SC3). Mercury content in steam coals was as follows: 138, 37 and 91 $\mu \mathrm{g} / \mathrm{kg}$ (dry basis). The effectiveness of mercury removal from coal in the thermal pretreatment process was determined using the Eq. (2).

$$
\eta_{t p}=\frac{H g_{\text {before }}-\gamma_{\text {after }} \cdot H g_{\text {after }}}{H g_{\text {before }}} \cdot 100 \%
$$

$\eta_{t p}$ - effectiveness of mercury removal from coal in the process of thermal pretreatment [\%],

$H g_{\text {before }}$ - mercury content in coal before thermal pretreatment $[\mu \mathrm{g} / \mathrm{kg}]$,

$\mathrm{Hg}_{\text {after }}--$ mercury content in coal after thermal pretreatment $[\mu \mathrm{g} / \mathrm{kg}]$,

$\gamma_{\text {after }}-$ yield of coal after thermal pretreatment [-]. 


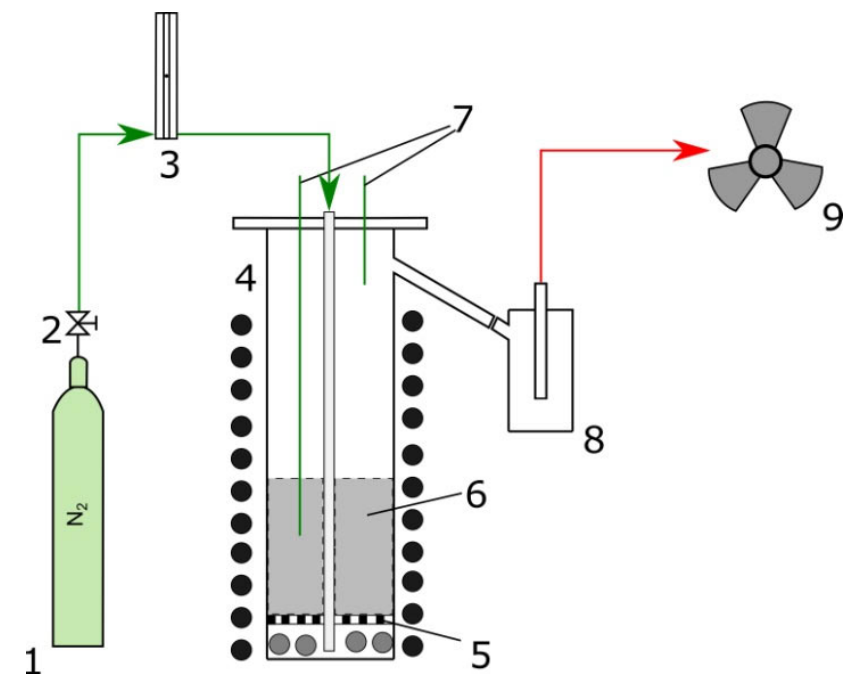

Fig. 1. Bench scale laboratory equipment for coal thermal pretreatment in fixed bed (1 - purge gas cylinder, 2 - gas reducer with control valve, 3 - rotameter, 4 - retort placed in oven, 5 - grid, 6 - coal, 7 - thermocouples, 8 - cooler, 9 - exhaust).

Additionally, the influence of the thermal pretreatment process of coal on its properties was studied. For this purpose, examinations of six coals widely used by domestic cokeries and coal fired power plants were performed (three coking coals and three steam coals). For all the selected coals, changes in calorific value and sulfur content were examined. In the case of coking coals, changes of dilatometric parameters were additionally studied. The characteristics of the examined coals are given in Table 2.

Table 2. Characteristics of hard coals used for examinations of changes in coal properties in the process of thermal pretreatment

\begin{tabular}{|l|l|c|c|c|c|c|c|c|}
\hline \multirow{2}{*}{\multicolumn{1}{|c|}{ Parameter }} & \multirow{2}{*}{ Symbol } & \multirow{2}{*}{ Unit } & \multicolumn{3}{c|}{ Coking coals } & \multicolumn{3}{c|}{ Steam coals } \\
\cline { 4 - 10 } & & & $\mathbf{C C 1}$ & $\mathbf{C C 2}$ & $\mathbf{C C 3}$ & $\mathbf{S C 1}$ & SC2 & SC3 \\
\hline Moisture & $\mathrm{M}^{\text {ad }}$ & $\%$ & 2.0 & 1.3 & 1.5 & 9.1 & 3.3 & 2.4 \\
\hline Ash & $\mathrm{A}^{\text {ad }}$ & $\%$ & 8.1 & 6.4 & 10.0 & 7.1 & 29.2 & 35.2 \\
\hline Volatile matter & $\mathrm{VM}^{\text {daf }}$ & $\%$ & 31.0 & 20.5 & 23.8 & 38.1 & 35.9 & 34.7 \\
\hline Lower heating value & $\mathrm{LHV}^{\text {ad }}$ & $\mathrm{kJ} / \mathrm{kg}$ & 30813 & 32083 & 30753 & 24229 & 20233 & 18926 \\
\hline Sulfur & $\mathrm{S}_{\mathrm{t}}{ }^{\mathrm{d}}$ & $\%$ & 0.68 & 0.44 & 0.59 & 1.11 & 0.96 & 0.61 \\
\hline Mercury & $\mathrm{Hg}_{\mathrm{t}}{ }^{\mathrm{d}}$ & $\mu \mathrm{g} / \mathrm{kg}$ & 60 & 62 & 106 & 46 & 100 & 207 \\
\hline
\end{tabular}

\subsection{Identification of the occurrence of the synergy effect resulting from the combination of both processes}

For the identification of the occurrence of the synergy effect resulting from the combination of coal cleaning and thermal pretreatment process, examinations were performed of three cases of feed and clean coal produced in selected sections of the coal processing plant - Table 3. Subsequently, in accordance with the method described in paragraph 3.2 , the thermal pretreatment of clean coals was conducted. 
Table 3. Mercury content in feed and clean coals produced in selected sections of the coal processing plant used for the identification of the occurrence of the synergy effect resulting from the combination of coal cleaning and thermal pretreatment process

\begin{tabular}{|c|c|c|c|}
\hline \multirow{2}{*}{$\begin{array}{c}\text { Analyzed } \\
\text { case }\end{array}$} & \multirow{2}{*}{$\begin{array}{c}\text { Coal } \\
\text { preparation } \\
\text { section }\end{array}$} & \multicolumn{2}{|c|}{$\begin{array}{c}\mathbf{H g}_{\mathbf{t}} \mathbf{d} \\
{[\mathbf{\mu g} / \mathbf{k g}]}\end{array}$} \\
\cline { 3 - 4 } & jeed coal & Clean coal \\
\hline SE1 & jigging & 148 & 114 \\
\hline SE2 & jigging & 45 & 30 \\
\hline SE3 & $\begin{array}{c}\text { dense media } \\
\text { separation }\end{array}$ & 114 & 40 \\
\hline
\end{tabular}

\section{Influence of the selected method on the effectiveness of removing mercury from hard coal}

\subsection{Comparison of effectiveness of mercury removal from hard coal}

The determined effectiveness of mercury removal from hard coal in the analyzed processes of coal cleaning and thermal pretreatment was presented in Fig.2. For each of the analyzed methods, mercury removal effectiveness was significant, although higher effectiveness was observed for the cleaning process, both washing and dry deshaling. The mercury removal effectiveness in the coal cleaning process ranged from 8 to $96 \%$ (coking coal washing: 21 $76 \%$; dry deshaling of steam coals: $8-96 \%$ ), and in the coal thermal pretreatment at $300{ }^{\circ} \mathrm{C}$ it ranged from 45 to $70 \%$. In view of the obtained results, it can be concluded that each of the analyzed methods could potentially be used for reducing mercury emissions from the coal utilization processes. Nevertheless, the analyzed methods show a wide variation in effectiveness, especially for the coal cleaning process.

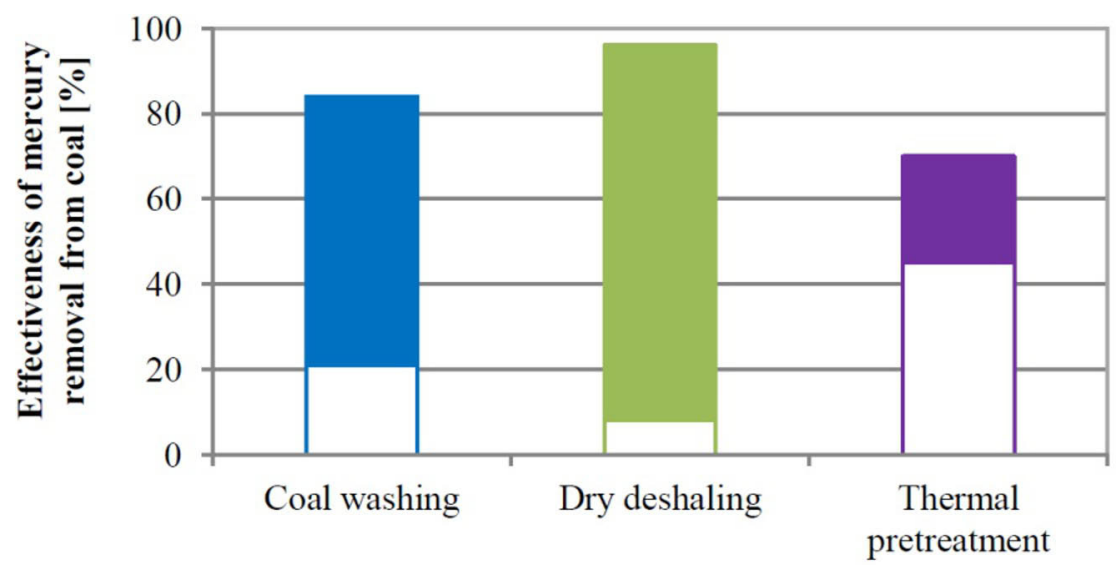

Fig. 2. Comparison of mercury removal efficiency from hard coal in processes of coal cleaning and coal thermal pretreatment

An increase in the amount of mercury removal from coal could be obtained by the combination of coal cleaning and coal thermal pretreatment. The synergy effect resulting from the combination of these methods is presented in Fig. 3. For each of the analyzed cases, the beneficial effect was obtained. 


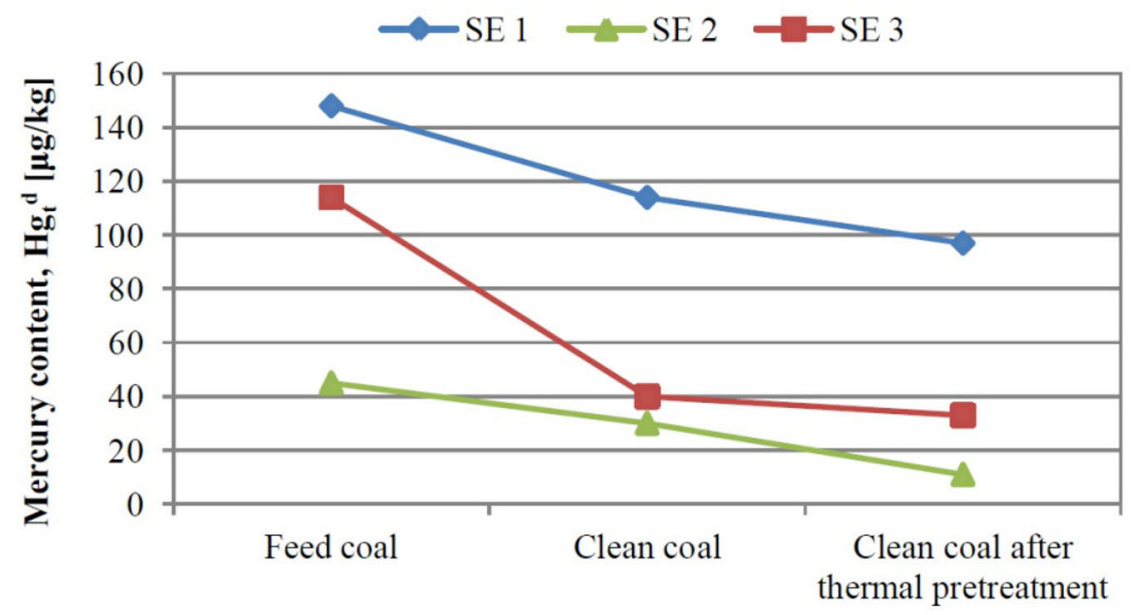

Fig. 3. Changes of mercury content in hard coal resulting from the combination of coal washing and thermal pretreatment at $300^{\circ} \mathrm{C}$

\subsection{The influence of the thermal pretreatment process of coal on its properties}

In most of the investigated samples, the process of coal thermal pretreatment at $300^{\circ} \mathrm{C}$ allows for an improvement in the quality of coal, i.e.: a decrease in moisture content, an increase in the calorific value (Fig. 4) as well as partial sulfur removal (Fig. 5). Thus, the application of this process will enhance the properties of hard coal used for heat and power production.

Nevertheless, the process of thermal pretreatment $\left(300^{\circ} \mathrm{C}\right)$ may result in a deterioration in the coking properties, which limits the applicability of this method for coking coals. The changes of dilatometric parameters are shown in Table 4. Especially significant changes were observed for maximum dilatation (b).

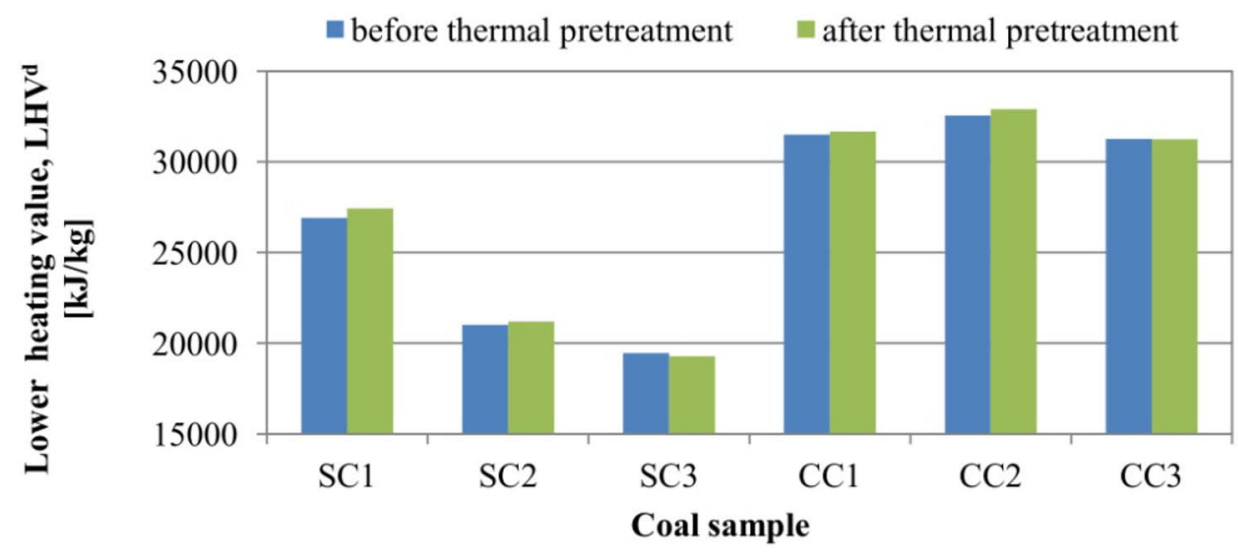

Fig. 4. Changes of lower heating value of hard coals in the process of thermal pretreatment at $300{ }^{\circ} \mathrm{C}$. 


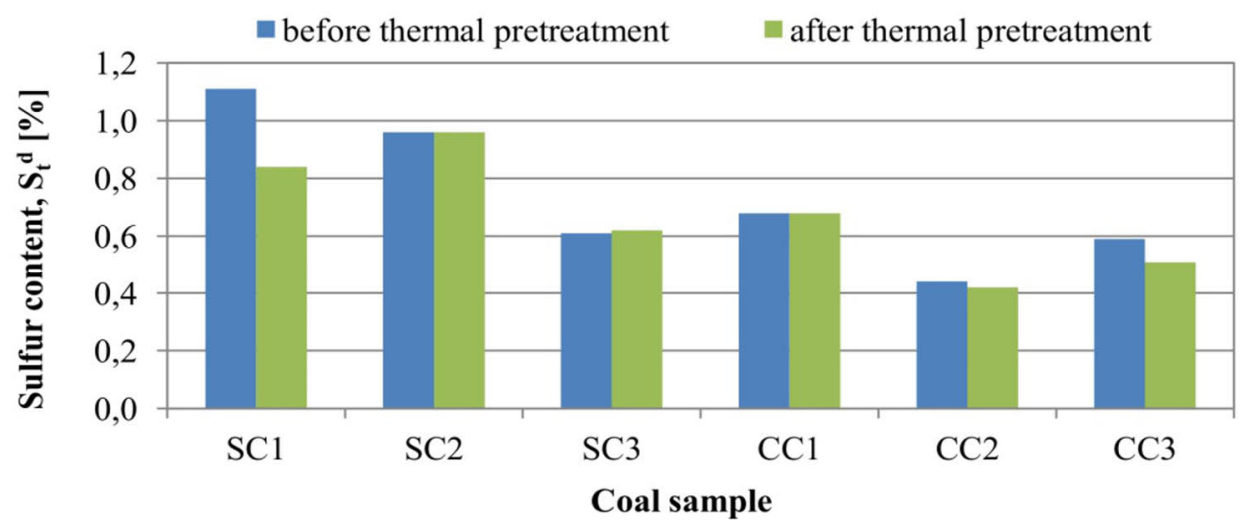

Fig. 5. Changes of sulfur content in hard coals in the process of thermal pretreatment at $300{ }^{\circ} \mathrm{C}$.

Table 4. Changes of dilatometric parameters in coking coals in the process of thermal pretreatment at $300^{\circ} \mathrm{C}$.

\begin{tabular}{|l|l|c|c|c|c|c|}
\hline \multicolumn{2}{|c|}{ Analyzed coal samples } & $\begin{array}{c}\mathbf{t}_{\text {I }} \\
{\left[{ }^{\circ} \mathbf{C}\right]}\end{array}$ & $\begin{array}{c}\mathbf{t}_{\text {II }} \\
{\left[{ }^{\circ} \mathbf{C}\right]}\end{array}$ & $\begin{array}{c}\mathbf{t}_{\text {III }} \\
{\left[{ }^{\circ} \mathbf{C}\right]}\end{array}$ & $\begin{array}{c}\mathbf{a} \\
{[\%]}\end{array}$ & $\begin{array}{c}\mathbf{b} \\
{[\%]}\end{array}$ \\
\hline \multirow{2}{*}{$\mathrm{CC} 1$} & before thermal pretreatment & 387 & 436 & 469 & 29 & 43 \\
\cline { 2 - 7 } & after thermal pretreatment & 372 & 440 & 467 & 21 & -5 \\
\hline \multirow{2}{*}{$\mathrm{CC} 2$} & before thermal pretreatment & 408 & 453 & 485 & 28 & 16 \\
\cline { 2 - 7 } & after thermal pretreatment & 414 & 547 & 550 & 25 & -24 \\
\hline \multirow{2}{*}{$\mathrm{CC} 3$} & before thermal pretreatment & 394 & 443 & 481 & 30 & 58 \\
\cline { 2 - 7 } & after thermal pretreatment & 403 & 469 & 490 & 28 & -27 \\
\hline
\end{tabular}

$\mathrm{t}_{\mathrm{I}}$ - softening temperature; $\mathrm{t}_{\mathrm{II}}$ - temperature of maximum contraction, $\mathrm{t}_{\mathrm{II}}$ - temperature of maximum dilatation; $\mathrm{a}$ - maximum contraction; $\mathrm{b}$ - maximum dilatation.

\subsection{Guidelines for the selection of a method for mercury removal from coking coal}

The recommended methods of mercury removal from coking coals are presented in Fig. 6. In the case of coking coals, mercury removal should be based on the coal washing process, which is already commonly used. Practically, only this method could ensure a coal quality which is required by the customers (the content of ash, sulfur and alkaline compounds as well as coking properties, etc.). In the case of coking coals, due to a deterioration in the coking properties of coal, the process of thermal pretreatment at the temperature of $300{ }^{\circ} \mathrm{C}$ or higher is not acceptable.

The additional possibility of mercury removal from coking coals depends on the type of coke oven battery. In the case of cokeries using gravity charging coke oven batteries, a further mercury removal is possible by applying the coal pre-drying process. The coal predrying process is used for increasing the bulk density of coal in the coke oven chamber. This improves the quality of the produced coke or gives an opportunity to increase the share of semi-soft coking coals in the blend instead of more expensive and less widely available hard coking coals, without a deterioration in the quality of the produced coke. The coal pre-drying process is conducted at $200{ }^{\circ} \mathrm{C}$, at which temperature the deterioration of the coking properties of coal does not take place [17]. In this range of temperatures, there occurs a partial mercury removal from coal. Thus, the additional possibility of mercury removal from coal 
could be obtained without applying a separate unit, because it would take place in the coal pre-drying unit. It should be pointed out, that the implementation of the coal pre-drying process will require removing mercury from process gases using sorbents. In the case of cokeries using the coke dry quenching technology, coke dust could be used as a sorbent [18].

In the case of cokeries using stamp charging coke oven batteries, mercury could be removed from coal only in the washing process.

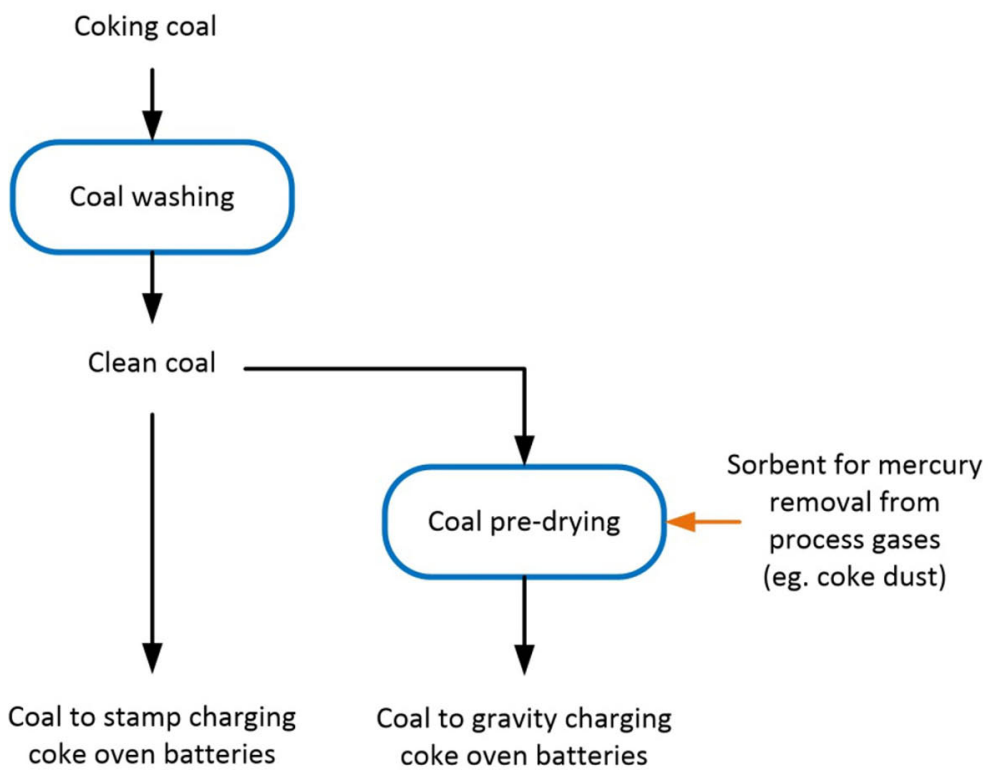

Fig. 6. Block diagram of recommended methods of mercury removal from coking coals

It should be mentioned that in the process of coal washing the middling products are also produced, which are widely used for heat and power production. In the case of a high mercury content in the middling products, its removal could be obtained in the process of thermal pretreatment.

\subsection{Guidelines for the selection of a method for mercury removal from steam coal}

The block diagram of the proposed methods of mercury removal from steam coals is presented in Fig. 7. For all steam coals, the dry deshaling process is recommended. This process allows for the removal of mercury as well as a decrease in ash content and thus an increase in calorific value.

The additional possibility of mercury removal from steam coal is provided by the thermal pretreatment of clean coal from the dry deshaling process. The performed analysis of the combination of the coal cleaning and thermal pretreatment process has shown the synergy effect. Nevertheless, the application of such a combination is recommended only for coals in which mercury occurs in organic matter as well as in the inorganic constituents characterized by a low temperature of mercury release. In order to determine the applicability of the combination of the coal cleaning and thermal pretreatment process, bench scale examinations are necessary. It is worth mentioning that the thermal pretreatment of coal would provide additional benefits in the form of an improvement in the quality of steam coal (e.g. a decrease in sulfur content). 
The proposed methods of mercury removal from steam coal enable the production of low-mercury coal for power stations, combined heat and power plants, gasification plants, as well as low-mercury household fuel.

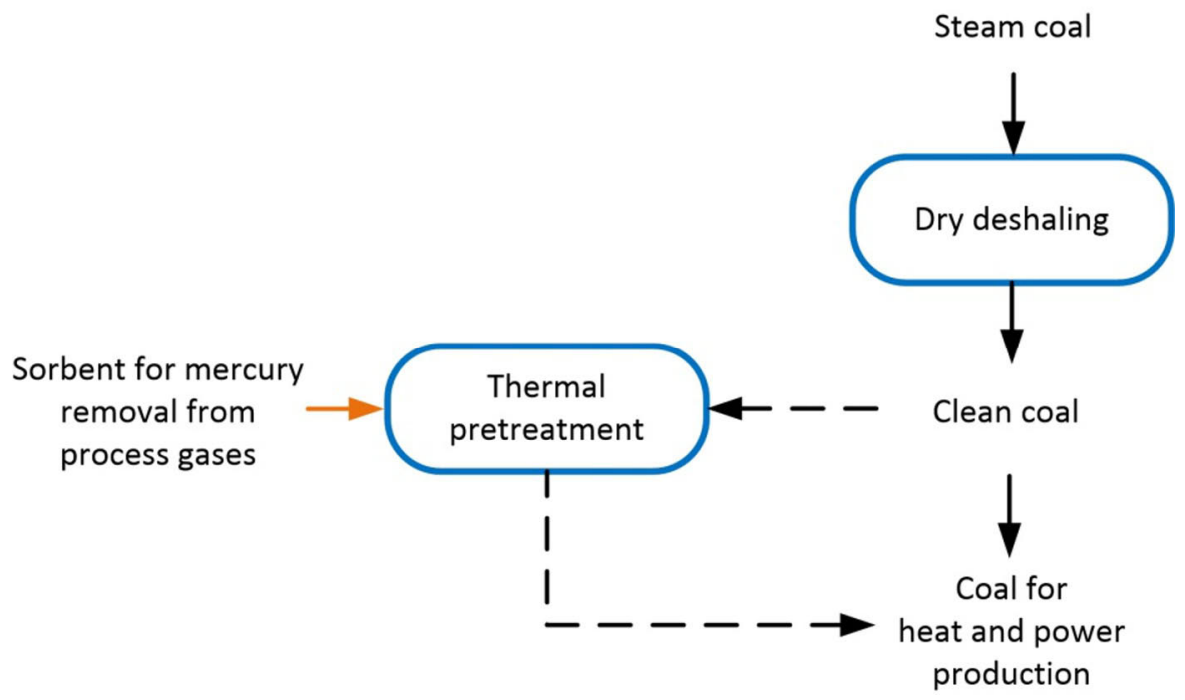

Fig. 7. Block diagram of recommended methods of mercury removal from steam coals.

It should be pointed out that, mercury removal from steam coal can also be performed in the process of coal washing. This particularly applies to coals, for which ensuring quality parameters (e.g. limits of ash content and heating value) requires the application of the coal washing process.

\section{Conclusions}

Each of the analyzed methods i.e. coal washing, dry deshaling, thermal pretreatment and the combination of these methods allows for the removal of mercury. However, it should be pointed out, that the selection of an appropriate method should take into account the effectiveness of mercury removal from coal, the direction of coal utilization as well as the influence of the analyzed methods on coal properties. For the removal of mercury from hard coal, depending on the direction of its utilization, the following methods are proposed:

- for coking coals used in stamp charging coke oven batteries - the coal washing process,

- for coking coals used in gravity charging coke oven batteries - the coal washing process combined with the coal pre-drying process,

- for steam coal - the dry deshaling process; in the case of coal for which ensuring the quality parameters is required - the coal washing process,

- for steam coal in which mercury occurs in organic matter as well as in the inorganic constituents characterized by low temperature of mercury release - the dry deshaling process combined with the thermal pretreatment process. 


\section{References}

1. R. Eisler, Mercury hazards to living organisms, (Taylor and Francis Group, Boca Raton 2006).

2. B. Gworek, J. Rateńska, Environmental Protection and Natural Resources 41, 614-623 (2009) [in Polish].

3. L.L. Sloss, Scientific and Industrial Conference, Krakow (2015).

4. E.G. Pacyna, J.M. Pacyna, F. Steenhuisen, S. Wilson, Atmos. Environ. 40, 4048-4063 (2006).

5. P. Burmistrz, K. Kogut, M. Marczak, J. Zwoździak, Fuel Process. Technol. 152, 250258 (2016).

6. PSE S.A., Miesięczne raporty $z$ funkcjonowania Krajowego Systemu Elektroenergetycznego $i$ Rynku Bilansujacego, (2016) [in Polish], http://www.pse.pl/index.php?modul=8\&id_rap=212.

7. Ministry of Economy of the Republic of Poland, Prognoza zapotrzebowania na paliwa $i$ energie do 2030 roku, Warszawa (2009) [in Polish].

8. T. Wenecki, M. Jarno, Koksownictwo Conference, Karpacz (2015) [in Polish].

9. M. Mastalerz, A. Drobniak, Int. J. Coal. Geol. 62, 223-236, (2005).

10. T. Dziok, S. Strugała, A. Rozwadowski, M. Macherzyński, A. Ziomber, Mineral Resources Management, 31(1), 107-122, (2015) [in Polish].

11. F.D. Guffey, E.A. Bland, Fuel Process. Technol. 85, 521-531 (2004).

12. T. Chmielniak, E. Misztal, I. Mazurek, M. Sajdak, Przem. Chem. 94(4), 480-486 (2015) [in Polish].

13. T. Dziok, S. Strugała, A. Rozwadowski, A. Okońska. Przem. Chem. 93(12), 2034-2037 (2014) [in Polish].

14. S.F. Diehl, M.B. Goldhaber, J.R. Hatch, Int. J. Coal. Geol. 59, 193-208 (2004).

15. A. Ohki, K. Sagayama, S. Tanamachi, Powder Technol. 180, 30-34 (2008).

16. Ł. Uruski, J. Górecki, M. Macherzyński, T. Dziok, J. Gołaś, Fuel Process. Technol. 140, 12-20 (2015).

17. P. Żarczyński, Doctoral dissertation, AGH University of Science and Technology, Faculty of Energy and Fuels, Krakow (2015) [in Polish].

18. P. Burmistrz (red.), Fuels technology - challenges and opportunities, Collective work, (Faculty of Energy and Fuels, AGH University, Kraków, 2016) [in Polish]. 